\title{
Effect of partial cryoablation on retinopathy of prematurity
}

\author{
Ilana Nissenkorn, Ruth Axer-Siegel, Israel Kremer, Isaac Ben-Sira
}

\begin{abstract}
Cryotherapy has been shown to be an effective treatment for retinopathy of prematurity stage 3. It is said to reduce the unfavourable outcome of the disease by $50 \%$. The accepted method of therapy includes ablation of the whole avascular retina from the ridge to the ora serrata. This is achieved by two to three rows of cryoapplications. When $360^{\circ}$ cryo treatment is performed, it requires 52 cryo applications. We present our method of cryotherapy which involves only one row of cryoapplications in the avascular retina anterior to the fibrovascular ridge. An average of 25-30 cryoapplications was required for a $360^{\circ}$ treatment. The anatomical results in 23 babies are presented. Complete regression of active retinopathy was found in all.
\end{abstract}

The first reports ${ }^{1-3}$ of the use of cryotherapy in the control of the proliferative phases of retinopathy of prematurity (ROP) varied in their conclusions regarding the advantages and limitations of this form of treatment.

In 1978 Kingham $^{4}$ published his disappointing clinical results following cryotherapy. In the same year Hindle and Leyton ${ }^{5}$ reported their successful clinicopathological results in the treatment of active ROP by cryotherapy. Their methods of treatment was similar to that used in the previous reports ${ }^{1-4}$ and consisted of direct freezing of the ridge and the adjacent areas anterior and posterior to it by one to two circular rows of cryoapplications. ${ }^{5}$ Hindle and Leyton showed that in most of the treated eyes the ridge disappeared and no cicatrisation developed. Keith, using the same direct method of cryoablation of the ridge but not the avascular retina anterior to it, found no beneficial effect. ${ }^{6}$

In contrast to that method of treatment ${ }^{1-6}$ BenSira and colleagues ${ }^{7}$ described an indirect treatment scheme involving cryoablation of the whole avascular retina, while avoiding direct treatment of the ridge and the neovascular growths posterior to it. ${ }^{7}$ Nissenkorn and coworkers reported a clinicopathological case which showed almost complete regression of the disease in the areas posterior to the atrophic chorioretinal cryo scars and low-grade active disease between the scars. ${ }^{8}$ Subsequently additional reports presented encouraging results following the use of the latter indirect method of cryo treatment. ${ }^{9-12}$

The encouraging preliminary results of the multicentre trial of cryotherapy for retinopathy of prematurity were published in $1988 . .^{12}$ The method of cryotherapy described included ablation of the whole avascular retina, from the ridge to the ora serrata, while avoiding the ridge itself. It was found that cryotherapy conferred an approximately $50 \%$ reduction in the unfavourable outcome of ROP. ${ }^{12}$

During the last three years we observed that cryotherapy involving ablation only of the avascular retina close to the ridge, by one row of cryoapplications, without reaching the ora serrata, leads to regression of the neovascular growths. We present here the results of this mode of partial cryotherapy performed in the premature babies under our care in the last three years.

\section{Patients and methods}

The charts of all premature babies undergoing cryotherapy due to ROP stage 3 from January 1986 to December 1988 were reviewed. All babies had a birth weight of less than $1250 \mathrm{~g}$ and gestational age of less than 28 weeks, except for one neonate whose gestational age was 32 weeks (Table 1). These 23 infants were found to have ROP stage 3 (moderate). The treatment was performed in zone $I$ in six infants ( 12 eyes) and in zone II in 17 infants (32 eyes). The cryoablation was performed differently from our previous treatment protocol, which we applied until $1986 .{ }^{7}$

The cryotherapy was done with a standard retinal probe. One row of contiguous applications were applied to the avascular retina, reaching the anterior edge of the ridge. The rest of the anteriorly located avascular retina was left untreated. The end point of each application was whitening of the retina. A freezing time of 3 to 4 seconds was usually needed to produce the necessary cryo effect in the retina. Treatment of

Table 1 Patients' clinical data

\begin{tabular}{|c|c|c|c|c|c|c|c|c|c|}
\hline \multirow[b]{2}{*}{ Case } & \multirow{2}{*}{$\begin{array}{l}\text { Treated } \\
\text { eye }\end{array}$} & \multirow{2}{*}{$\begin{array}{l}\text { GA } \\
\text { (weeks) }\end{array}$} & \multirow{2}{*}{$\begin{array}{l}B W \\
(g)\end{array}$} & \multicolumn{2}{|c|}{$\begin{array}{l}\text { Zone } \\
\text { of ROP }\end{array}$} & \multicolumn{2}{|c|}{$\begin{array}{l}\text { Extent of } \\
\text { ROP }\end{array}$} & \multicolumn{2}{|c|}{$\begin{array}{l}\text { Cryoablation } \\
\text { (hours) }\end{array}$} \\
\hline & & & & $R E$ & $L E$ & $R E$ & $L E$ & $R E$ & $L E$ \\
\hline 1 & $\mathrm{BE}$ & 28 & 690 & II & II & 12 & 12 & 12 & 12 \\
\hline 2 & $\mathrm{BE}$ & 26 & 790 & I & I & 12 & 12 & 12 & 12 \\
\hline 3 & $\mathrm{BE}$ & 25 & 680 & I & I & 12 & 12 & 12 & 12 \\
\hline 4 & $\mathrm{BE}$ & 28 & 670 & I & I & 12 & 12 & 12 & 12 \\
\hline 5 & $\mathrm{BE}$ & 26 & 700 & II & II & 8 & 8 & 8 & 8 \\
\hline 6 & $\mathrm{BE}$ & 27 & 750 & II & II & 7 & 7 & 7 & 7 \\
\hline 7 & $\mathrm{BE}$ & 26 & 680 & I & I & 12 & 12 & 12 & 12 \\
\hline 8 & $\overline{B E}$ & 26 & 670 & I & I & 12 & 12 & 12 & 12 \\
\hline 9 & $\mathrm{BE}$ & 28 & 700 & II & II & 6 & 6 & 6 & 6 \\
\hline 10 & BE & 26 & 770 & II & II & 6 & 6 & 6 & 6 \\
\hline 11 & LE & 26 & 870 & II & II & - & 6 & - & 6 \\
\hline 12 & LE & 27 & 900 & II & II & - & 6 & - & 6 \\
\hline 13 & $\mathrm{BE}$ & 26 & 870 & II & II & 6 & 6 & 6 & 6 \\
\hline 14 & LE & 28 & 750 & II & II & - & 8 & - & 8 \\
\hline 15 & $\overline{B E}$ & 24 & 720 & I & I & 12 & 12 & 12 & 12 \\
\hline 16 & $\mathrm{BE}$ & 28 & 580 & II & II & 6 & 6 & 6 & 6 \\
\hline 17 & $\mathrm{BE}$ & 25 & 860 & II & II & 6 & 6 & 6 & 6 \\
\hline 18 & $\mathrm{BE}$ & 26 & 810 & II & II & 6 & 6 & 6 & 6 \\
\hline 19 & LE & 32 & 900 & II & II & - & 6 & - & 6 \\
\hline 20 & $\mathrm{BE}$ & 26 & 930 & II & II & 6 & 6 & 6 & 6 \\
\hline 21 & BE & 27 & 950 & II & II & 12 & 12 & 12 & 12 \\
\hline 22 & $\mathrm{BE}$ & 28 & 950 & II & II & 6 & 6 & 6 & 6 \\
\hline 23 & $\mathrm{BE}$ & 27 & 1120 & II & II & 6 & 6 & 6 & 6 \\
\hline
\end{tabular}

$\mathrm{GA}=$ gestational age $\mathrm{BW}=$ birth weight 


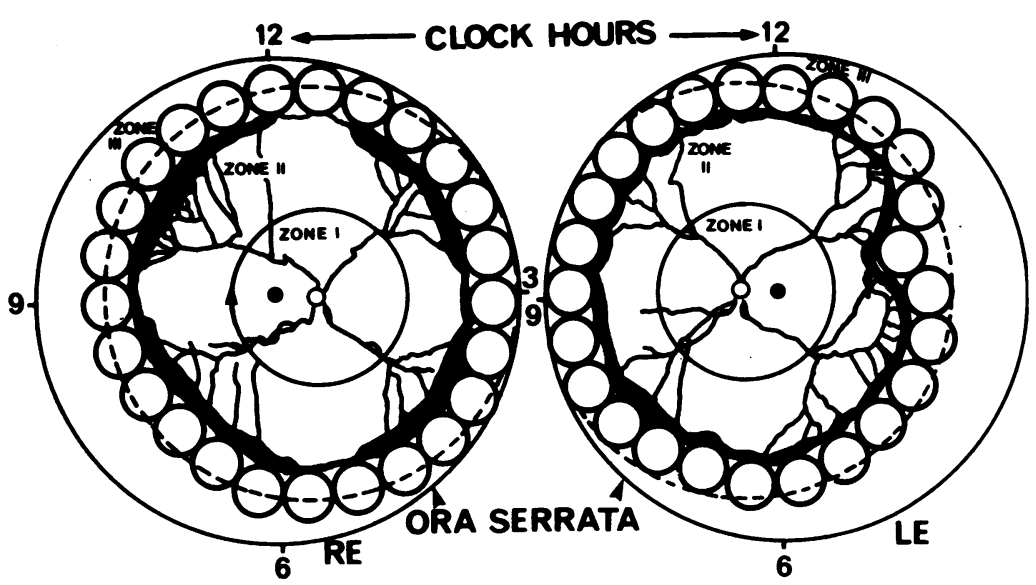

Figure 1 Schematic drawing of partial cryoablation treatment of ROP stage 3, zone II.

the entire circumference of the retina required an average of approximately 25-30 separate treatment spots (Fig 1). In most cases no conjunctival incision was required except for the very small premature babies in whom ROP was located in zone I.

Most of the babies underwent the treatment with topical anaesthetic drops (oxybuprocaine $0.4 \%$ ), while a neonatologist was in attendance. Six of the neonates who had vasoproliferative disease in zone I (cases 2, 3, 4, 7, 8, 15, Table 1) were treated under general anaesthesia. In those patients a conjunctival incision 3-4 $\mathrm{mm}$ in length was made in each quadrant, a cataract cryoprobe was inserted, and one row of cryoapplications was applied throughout $360^{\circ}$ in zone I. Postoperatively, 1 drop of atropine $0.5 \%$ and dexamethasone $1 \%$ were instilled three times a day for one week.

The infants underwent weekly examinations in the first month after treatment, followed by monthly examinations in the following three months, and once every six months thereafter. All infants underwent orthoptic evaluation and retinoscopy until 1 year of age.

\section{Results}

In most of the infants the disease was found to be symmetrical, and both eyes were treated with cryoablation (Table 1). The cryotherapy was performed at an average age of 6-12 weeks. In six infants with zone I disease the cryoablation was performed in both eyes throughout the whole retinal circumference ( 12 clock hours) (Table 1 ). Thirteen infants with bilateral zone II disease received cryotherapy extending from 6 to 12 clock hours in both eyes (Table 1). Four infants with asymmetrical disease had cryoablation performed in zone II in one eye only, for 6 clock hours (Table 1).

One week after cryoablation the dilatation and tortuosity of posterior pole vessels decreased, and two to four weeks later the active retinal and extraretinal vasoproliferations disappeared in the majority of the cases. In three cases with zone I disease where the cryoapplication did not reach the anterior edge of the ridge we had to add a few cryoapplications closer to the ridge, after which the regression occurred. The results of the two-year follow-up after cryotherapy based on fundus examination revealed total regression of the active vasoproliferative disease. Atrophic pigmented chorioretinal scars were found anterior to the equator in $70 \%$ of the babies and posterior to the equator in $30 \%$. No child developed retinal detachment.

The results of orthoptic evaluation, refraction, and visual acuity testing will be reported in the future.

\section{Discussion}

Animal studies have shown that the developing retinal vasculature responds in a biphasic way: (a) initial vasoconstriction and vaso-obliteration in the presence of raised arterial oxygen levels, and $(b)$, on return to room air, by peripheral retinal ischaemia with consequent neovascular proliferation, possibly due to secretion of a vasoproliferative substance by the ischaemic retina. ${ }^{13-15}$ Taylor $e t a l^{16}$ have shown that a vasoproliferative factor is released under these conditions. In $1984 \mathrm{Kretzer}$ et $a l^{17}$ described a theory for the induction of ROP according to which a high level of oxygen may trigger extensive gap junction formation between the spindle cells of the avascular vanguard retina, located close to the rearguard zone. Therefore it may be assumed that the development of ROP is triggered by a vasoproliferative substance produced in the ischaemic vanguard retina, as happens in other ischaemic retinopathies. ${ }^{18} 19$ The greater the stimulus in the area of the ischaemic retina to produce this substance, the greater the vasoproliferation, as for example in zone I retinopathy or Rush type ROP. ${ }^{20}$ As in other ischaemic retinopathies, destruction of the ischaemic tissue is believed to reduce the formation of this vasoproliferative factor and to arrest the vasoproliferative disease. ${ }^{2122}$ The main question confronting us since we started to perform cryotherapy in active stage $3 \mathrm{ROP}$ is how much avascular retina should be ablated. Between 1976 and 1983 we have been cryoablating the whole avascular retina, avoiding the ridge itself and the neovascular growths, according to a protocol which was described by Ben-Sira et al. ${ }^{23}$ Since 1986 we have changed the method of cryoablation by which the cryoapplications were performed only anterior to the ridge on the avascular retina, in one row. The rationale for this partial cryotherapy was that the main stimulus for neovascularisation is probably located in the avascular retina adjacent to the ridge, where the metabolic activity of the spindle cells is highest and where one can also find increased numbers of gap junctions. ${ }^{17}$ This method has proved to be successful in conferring regression of the neovascular proliferations posterior to the ridge, in all the above presented premature babies. No serious postoperative complications such as rhegmatogenous retinal detachment were noted. ${ }^{24}$

Therefore we are of the opinion that the treatment, to begin with, in a baby with ROP stage 3 should be partial cryoablation consisting of one or a maximum of two rows of cryoapplications in the avascular retina close to the ridge. The treatment must be done in a confluent pattern close to the ridge, and one must avoid gaps between the cryoablation spots (Fig 1). 
1 Payne J, Patz A. Treatment of acute retrolental fibroplasia. Trans Am Acad Ophthalmol 1972; 76: 1234-46.

2 Harris GS. Retinopathy of prematurity and retinal detach ment. Can F Ophthalmol 1976; 11: 21-5.

3 McCormick AQ. Retinopathy of prematurity: current problems. Pediatrics 1977; 7: 11-2.

4 Kingham JD. Acute retrolental fibroplasia II. Treatment by cryosurgery. Arch Ophthalmol 1978; 96: 2049-53.

5 Hindle NW, Leyton J. Prevention of cicatricial retrolental fibroplasia by cryotherapy. Can $\mathcal{F}$ Ophthalmol 1978; 13: 277 82.

6 Keith CG. Visual outcome and effect of treatment in stage III developing retrolental fibroplasia. $\mathrm{Br} \mathcal{F}$ Ophthalmol $1982 ; 66$ : 446-9.

7 Ben Sira I, Nissenkorn I, Grunwald E, Yassur Y. Treatment of acute retrolental fibroplasia by cryopexy. $\mathrm{Br} \mathcal{F}$ Ophthalmol $1980 ; 64: 758-62$.

8 Mousel DK. Cryotherapy for retinopathy of prematurity Ophthalmology 1985; 92: 375-8.

9 Nissenkorn I, Kremer I, Ben-Sira E, Cohen S, Garner A. A clinicopathological case of retinopathy of prematurity (ROP) treated by peripheral cryopexy. $\mathrm{Br} \mathcal{F}$ Ophthalmol 1984; 68: 36-41.

10 Tasman W. Management of retinopathy of prematurity. Ophthalmology 1985; 92: 995-9.

11 Tasman W, Brown GC, Schaffer DB, et al. Cryotherapy for active retinopathy of prematurity. Ophthalmology 1986; 93: active $580-5$.

12 Cryotherapy for retinopathy of prematurity cooperative group. Multicenter trial of cryotherapy for retinopathy of prematurity: preliminary results. Arch Ophthalmol 1988; 106: 471-9.

13 Ashton N, Ward B, Serpell G. Role of oxygen in the genesis of retrolental fibroplasia: a preliminary report. Brf Ophthalmol 1953; 37: 513-20.
14 Patz A, Eastham A. Higginbotham DH, Kleh T. Oxygen studies in retrolental fibroplasia II. The production of microscopic changes of retrolental fibroplasia in experimental animals. Am $\mathcal{f}$ Ophthalmol 1953; 36: 1511-22.

15 Ashton N, Ward B, Serpell G. Effect of oxygen on developin retinal vessels with particular reference to the problem of retrolental fibroplasia. Br f Ophthalmol 1954; 38: 397-432.

16 Taylor CM, Weiss JB, Kissum RD, Garner A. Effect of $\mathrm{O}_{2}$ tension on the quantities of procollagenase activating angiogenic factor present in the developing kitten retina. Brf Ophthalmol 1986; 70: 162-5.

17 Kretzer FL, Mehta RS, Johnson AT, Hunter DG, Brown ES, Hittner HM. Vitamin E protects against retinopathy of prematurity through action on spindle cells. Nature 1984; prematurity through action on spindle cells. Nature 1984;

8 Foos RY. Acute retrolental fibroplasia. Graefes Arch Clin Exp Ophthalmol 1975; 195: 87-100.

19 Ben-Sira I, Nissenkorn I, Kremer I. Retinopathy of prematurity: major review. Surv Ophthalmol 1988; 33: 1-16.

20 Nissenkorn I, Kremer I, Kilad E, Cohen S, Ben-Sira I. Rushtype retinopathy of prematurity - a report on four cases. Brf Ophthalmol 1987; 71: 559-62.

21 Tasman LN, Magargal L, Augsburger JJ. Effects of argon laser photocoagulation on rubeosis iridis and angle neovascularisation. Ophthalmology 1980; 87: 400-2.

22 May DR, Bergstrom TJ, Parmet AJ, Schwartz JG. Treatment of neovascular glaucoma with transcleral panretinal cryotherapy. Ophthalmology 1980;87: 1106-11.

23 Ben-Sira I, Nissenkorn I. Treatment of acute retrolental fibroplasia with cryotherapy. In: McPherson AR, Hittner HM, Kretzner FL, eds. Retinopathy of prematurity - current concepts and controversies. Toronto, Philadelphia: Decker, 1986: $129-41$.

24 Greven CM, Tasman W. Rhegmatogenous retinal detachment ollowing cryotherapy in retinopathy of prematurity. Arch Ophthalmol 1989; 107: 1017-8. 